\title{
Progress in Patients with Peptic Ulceration treated for more than Five Years with Poldine, including a Double-Blind Study
}

\author{
J. N. HUNT,* M.D., D.SC., PH.D. ; R. C. WALES,*† M.B., B.S.
}

Brit. med. F., 1966, 2, 13-16

The beneficial effect of vagotomy in patients with duodenal ulceration is believed to depend on the halving of the gastric secretion of acid which follows the operation, and which persists for at least three years (Bell, 1964). It would be advantageous if a similar reduction in secretion could be produced by blocking the action of the vagus nerves pharmacologically-for example, with an anticholinergic compound-without the occasional ill effects of surgical vagotomy. However, the orthodox view is that " the anticholinergic drugs do not reduce the acidity of the gastric contents in patients taking food, and their only real value is as antispasmodics" (B.M.F., 1963). The heterodox view is that atropine, and poldine methylsulphate (Nacton), as examples of drugs with tertiary and quaternary nitrogen, in doses which produce no side-effects, do inhibit gastric secretion of acid in response to food (Mitchell, Hunt, and Grossman, 1962).

An average reduction of the gastric secretion of acid by onehalf in a group of outpatients with peptic ulceration treated with poldine was reported four years ago (Douthwaite, Hills, and Hunt, 1961). Before this treatment they had been losing an average of 28 days' work a year, and had needed treatment in hospital at the beginning of the trial. During treatment they lost an average of only two days' work a year. However, it was not established that the improved clinical course resulted from a reduction in the gastric secretion of acid, since the patients were receiving monthly test meals and extra clinical interest. It was therefore decided to treat them under double-blind conditions. The present paper contains an account of the results and difficulties met with in so doing.

\section{Methods}

Test Meals.-The test-meal method used by Hunt (1954) gives the volumes of $160 \mathrm{mN}(160 \mathrm{mEq} / 1$.) hydrochloric acid, $45 \mathrm{mN}$ bicarbonate, and amounts of pepsin secreted in 30 minutes in response to $750 \mathrm{ml}$. of a solution of glucose in water.

Symptoms.-Every month the patients were given a card printed with a grid labelled with specific symptoms associated with peptic ulceration and expected side-effects of anticholinergic drugs. A space was available for each day, and each morning and evening the patients marked any relevant space with a cross. In this way a numerical assessment of symptoms and side-effects on an ordinal scale was possible. One symptom for a morning or an evening was counted as one symptom-unit.

Blood Tests.-A blood-film examination and the following estimations were carried out in a search for evidence of any long-term toxicity: haemoglobin, haematocrit, white blood cell and differential count, platelet count, blood urea, plasma bilirubin, serum glutamic pyruvic transaminase, and serum glutamic oxaloacetic transaminase.

Measurements of Intraocular Pressure.-Tonometry was carried out with a Schiötz tonometer at two different weights at a time when some of the patients were on inactive tablets

* Department of Physiology, Guy's Hospital Medical School, London. t Present address: Wilmer Institute, The Johns Hopkins Hospital, Baltimore, Maryland 21205, U.S.A. under double-blind conditions. The intraocular pressure was later checked in patients known to be on active tablets, applanation tonometry being used. A Schiötz weighted tonometer was used in an attempt to evaluate intraocular fluid dynamics, but this method was not regarded as entirely satisfactory.

\section{Present Investigation}

The present report concerns the continued progress in the 16 cases described four years ago (Douthwaite et al., 1961). One patient dropped out of the trial because he went abroad. Thirteen patients had suffered from duodenal ulcers and two from gastric ulcers.

In September 1961 the patients were told that a double-blind trial was desirable in order to discover whether their relative freedom from dyspepsia was the result of the support they were receiving in terms of monthly attendances for test meals, or whether it was due to treatment with poldine, presumably acting by reducing the secretion of acid in the stomach. It was pointed out to them that the recommendation that a drug should be taken continuously for life could be made only if there were compelling reasons for so doing. They were told that the double-blind trial would start at that time, but in fact active tablets were given to all in order to determine whether or not they would have dyspepsia as a consequence of the possible anxiety of being in a double-blind trial. In Table I this is referred to as patient-blind in the subperiod for 1961 .

In December 1961 half the patients were given inactive tablets and half had had active tablets under double-blind conditions.

In June 1962 the two groups were exchanged. The change was made from the patient's first set of tablets to hís second set gradually over a period of two to three weeks so that he would not experience side-effects as a result of a sudden change to active tablets. The doses chosen for the trial were given four times daily, after food, and, had previously been carefully adjusted for each patient so that they did not produce noticeable side-effects. The doses ranged from 8 to $44 \mathrm{mg}$., with a mean of $24 \mathrm{mg}$., daily. Close questioning of the patients showed that they had not been able, on the basis of side-effects, to decide whether or not they were having active tablets. They were also given a supply of aluminium glycinate antacid tablets (Prodexin) to take if required.

The distribution of active and inactive tablets remained unchanged from June 1962 to January 1965 . The patients were studied with test meals at monthly intervals throughout the trial. The first of the four daily doses of poldine was usually taken about 90 minutes before the test meal.

\section{Results}

In September 1961 the 15 patients were divided into two groups-eight in group I and seven in group II-in a completely random fashion by a person otherwise unconcerned in the trial. To evaluate the effects of prolonged treatment with poldine it was necessary to analyse, with the division into two 
groups, results from selected comparable periods of the study already reported, though the divisions and selections had not been made at that time.

For analysis and presentation the mean of the results for each patient for each specified period was calculated. The mean of the results for each group of patients for each period was calculated from these individual means, so giving equal weight to each patient.

Secretion of Acid.-The mean values of acid secreted in 30 minutes in response to the test meal for each patient are set out in Table I. The case numbers correspond to those in Table I of the previous report (Douthwaite et al., 1961). The mean values for groups I and II, separately and combined, are set out in Table II. The following points may be made: (1) While the patients were on active treatment over a period of two to four years their secretion of acid was $40 \mathrm{ml}$., compared with $78 \mathrm{ml}$. before treatment. (2) After two to four years of treatment the mean secretion of acid, as measured on inactive tablets for six months under double-blind conditions, was $66 \mathrm{ml}$. For group II, who continued on inactive tablets for two more years, there was no rise in secretion. (3) The reduction of secretion of acid by a constant dose of poldine in group I remained unchanged for periods from five to seven years. The findings in group II confirm this for the shorter period of treatment which these patients received.

Secretion of Alkaline Mucous Component.-The secretion of $45 \mathrm{mN}$ bicarbonate by the stomach under treatment with poldine was $26 \mathrm{ml}$. in 30 minutes, compared with $26 \mathrm{ml}$. on inactive tablets after two to four years of treatment and $35 \mathrm{ml}$. during the period in hospital before treatment. When the reduction of the secretion of acid and of bicarbonate were considered together it was found that the concentration of acid in the mixed gastric juice had fallen by one-quarter.

Secretion of Pepsin.-Pepsin was estimated in 27 tests on inactive tablets and 35 tests on active tablets during the doubleblind study. On inactive tablets the mean amount of pepsin for each millilitre of acid secretion was 160, S.E. \pm 12 , pepsin units ; on active tablets it was 109 , S.E. \pm 7 , pepsin units for each millilitre of acid secretion. These ratios indicate that poldine reduced the secretion of pepsin more than that of acid. The results are not shown in Table $I$.

Gastric Emptying.-There was a long-term increase in the rate of gastric emptying which more than offset the short-term slowing of emptying produced by poldine.

Intraocular Pressure.-There was no evidence of raised intraocular pressure. A high resistance to outflow was not always found in the patients with the highest pressures. In one patient with marked hypermetropia and shallow anterior chambers, on high doses of poldine, the stopping of treatment appeared to decrease his rather high outflow resistance, but his pressure went up slightly. However, he had the lowest pressure recorded in our patients on all occasions. The patient with the highest recorded pressure had a low resistance to outflow, but a slight drop in pressure was found after stopping treatment.

Toxic Effects.-No abnormal values were found in any blood examination, and no significant changes were observed on comparison with the results of previous tests.

TABLE I.-Millilitres of Parietal Component (160 mN HCl) Secreted in 30 Minutes in Response to a 750-ml. Test Meal Containing $50 \mathrm{~g}$. of Glucose per Litre. Each Value is the Mean of Three to Six Results. Values in Bold Type are for Tests with Active Tablets

\begin{tabular}{|c|c|c|c|c|c|c|c|c|c|c|c|c|c|}
\hline \multirow[b]{2}{*}{$\begin{array}{l}\text { Case } \\
\text { No. }\end{array}$} & \multicolumn{2}{|c|}{ In-patient } & \multicolumn{4}{|c|}{ Previous Results } & \multicolumn{7}{|c|}{ Double-blind Trial } \\
\hline & $\begin{array}{c}\text { In } \\
\text { Hospital } \\
1957 . \\
\text { Untreated } \\
1958 \\
\end{array}$ & $\begin{array}{c}\text { First } \\
\text { Six } \\
\text { Months } \\
\text { Active } \\
\text { Treatment } \\
\end{array}$ & $\begin{array}{c}\text { Two } \\
\text { Months } \\
\text { on Inactive } \\
\text { Tablets. } \\
1960\end{array}$ & $\begin{array}{l}\text { Interim } \\
\text { Period } \\
\text { of } \\
\text { Twelve } \\
\text { Months } \\
\end{array}$ & $\left|\begin{array}{c}\text { Six } \\
\text { Months } \\
\text { before } \\
\text { Blind Trial. } \\
1961\end{array}\right|$ & $\begin{array}{c}\text { Patient- } \\
\text { blind } \\
\text { Period. } \\
1961\end{array}$ & \begin{tabular}{|} 
First \\
Six \\
Months \\
on Active. \\
1962
\end{tabular} & $\begin{array}{c}\text { First } \\
\text { Two } \\
\text { Months } \\
\text { on Inactive. } \\
1962\end{array}$ & $\begin{array}{c}\text { First } \\
\text { Six } \\
\text { Months } \\
\text { on Inactive. } \\
1962\end{array}$ & $\begin{array}{c}\text { Third } \\
\text { Six } \\
\text { Months. } \\
1963\end{array}$ & $\begin{array}{c}\text { Fourth } \\
\text { Six } \\
\text { Months. } \\
1963\end{array}$ & $\begin{array}{c}\text { Fifth } \\
\text { Six } \\
\text { Months. } \\
1964\end{array}$ & $\begin{array}{c}\text { Sixth } \\
\text { Six } \\
\text { Months. } \\
1964\end{array}$ \\
\hline $\begin{array}{r}1 \\
4 \\
8 \\
9 \\
11 \\
12 \\
15 \\
16\end{array}$ & $\begin{array}{r}83 \\
103 \\
126 \\
70 \\
86 \\
96 \\
51 \\
111\end{array}$ & $\begin{array}{r}29 \\
53 \\
107 \\
38 \\
42 \\
48 \\
20 \\
60\end{array}$ & $\begin{array}{r}\overline{49} \\
168 \\
79 \\
78 \\
88 \\
55 \\
95\end{array}$ & $\begin{array}{l}35 \\
68 \\
87 \\
44 \\
55 \\
48 \\
23 \\
45\end{array}$ & $\begin{array}{l}33 \\
65 \\
72 \\
40 \\
32 \\
45 \\
35 \\
59\end{array}$ & $\begin{array}{c}\text { Grou } \\
4 J \\
62 \\
100 \\
4 J \\
32 \\
37 \\
33 \\
49\end{array}$ & \begin{tabular}{|ll} 
& \\
$\mid$ & 38 \\
& 57 \\
& 82 \\
& 40 \\
& \\
& 32 \\
& 64 \\
& 64 \\
& 25 \\
& 70
\end{tabular} & $\begin{array}{r}43 \\
70 \\
125 \\
89 \\
43 \\
110 \\
33 \\
77\end{array}$ & $\begin{array}{r}53 \\
93 \\
143 \\
92 \\
65 \\
95 \\
35 \\
85\end{array}$ & $\begin{array}{l}40 \\
60 \\
96 \\
37 \\
25 \\
55 \\
22 \\
68\end{array}$ & $\begin{array}{r}47 \\
56 \\
118 \\
42 \\
34 \\
55 \\
25 \\
52\end{array}$ & $\begin{array}{r}46 \\
54 \\
112 \\
44 \\
31 \\
50 \\
17 \\
51\end{array}$ & $\begin{array}{r}44 \\
56 \\
130 \\
39 \\
28 \\
54 \\
19 \\
50\end{array}$ \\
\hline $\begin{array}{r}2 \\
3 \\
5 \\
6 \\
7 \\
10 \\
13\end{array}$ & $\begin{array}{l}58 \\
98 \\
54 \\
69 \\
46 \\
32 ! \\
94\end{array}$ & $\begin{array}{l}28 \\
63 \\
14 \\
37 \\
16 \\
21 \\
27\end{array}$ & $\begin{array}{l}48 \\
96 \\
77 \\
52 \\
26 \\
88\end{array}$ & $\begin{array}{l}15 \\
46 \\
12 \\
49 \\
15 \\
21 \\
35\end{array}$ & $\begin{array}{l}15 \\
80 \\
12 \\
43 \\
27 \\
19 \\
44\end{array}$ & $\begin{array}{l}\text { Grou } \\
14 \\
46 \\
20 \\
45 \\
20 \\
20 \\
36\end{array}$ & \begin{tabular}{|ll} 
p II & \\
$\quad$ & 19 \\
& 65 \\
& 34 \\
& 46 \\
& 32 \\
& 18 \\
& 49
\end{tabular} & $\begin{array}{l}17 \\
61 \\
59 \\
57 \\
36 \\
15 \\
70\end{array}$ & $\begin{array}{l}23 \\
61 \\
48 \\
77 \\
32 \\
20 \\
65\end{array}$ & $\begin{array}{l}15 \\
75 \\
24 \\
73 \\
42 \\
21 \\
69\end{array}$ & $\begin{array}{l}15 \\
66 \\
29 \\
71 \\
35 \\
17 \\
53\end{array}$ & $\begin{array}{l}21 \\
69 \\
53 \\
58 \\
34 \\
29 \\
79\end{array}$ & $\begin{array}{l}13 \\
60 \\
44 \\
62 \\
27 \\
68\end{array}$ \\
\hline
\end{tabular}

TABLe II.-Millilitres of Parietal Component $(160 \mathrm{mN} \mathrm{HCl}$ ) Secreted in 30 Minutes in Response to a 750-ml. Test Meal Containing $50 \mathrm{~g}$. of Glucose per Litre. Each Mean for the Group Gives Equal Weight to Each Patient. Values in Bold Type are for Tests with Active Tablets

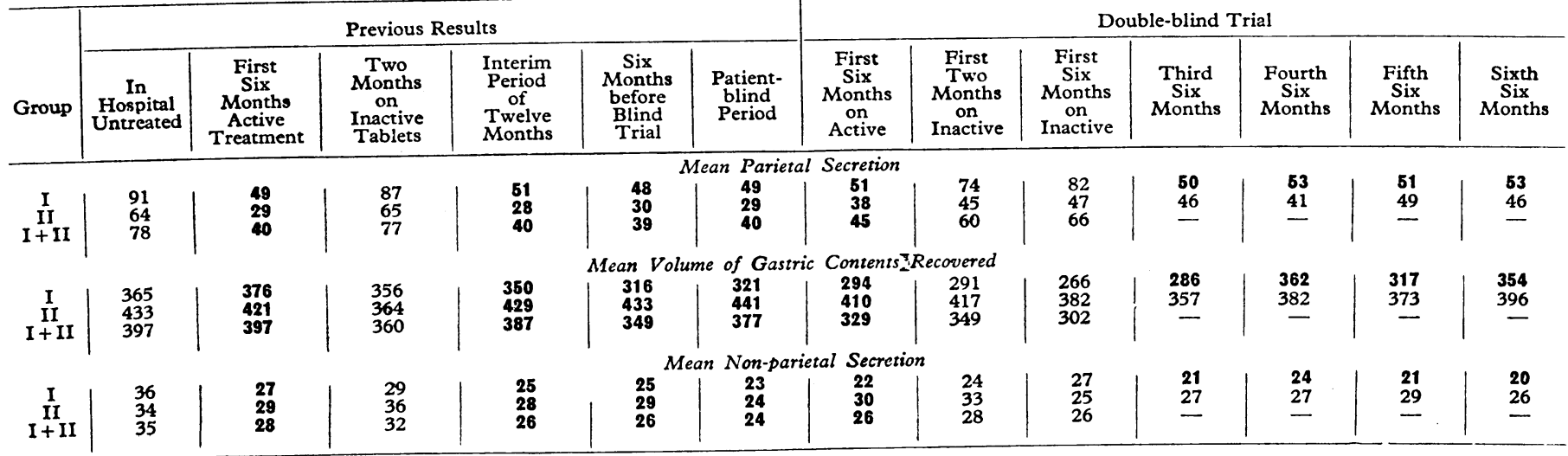




\section{Discussion}

\section{Basis of Treatment}

There is evidence that peptic ulceration is a self-limiting disorder, provided that the patients survive the complications (Fry, 1964). A treatment which relieved the pain and prevented complications occurring during the years of activity of the disorder would be a logical development.

Chronic peptic ulceration is usually ascribed to diminished mucosal resistance and relatively increased gastric secretion of acid. In the control of gastric secretion acetylcholine released by vagal terminations has direct stimulant and potentiating actions in the cephalic and gastric phases of the gastric secretion of acid (Grossman, 1963). Reduction of vagal activity can therefore be regarded as a specific treatment of one of the factors underlying peptic ulceration. Surgical vagotomy reduces the secretion of acid, but surgery entails time off work for the patients, and occasionally produces irreversible ill effects. Reversible pharmacological blockade of cholinergic activity would seem to be preferable to vagotomy, but it must be achieved with a drug which gives the continuous reduction of the gastric secretion of acid without the other effects of anticholinergic compounds, such as dryness of the mouth, blurring of near vision, and retention of urine. This would offer the possibility of patients with peptic ulceration reaching the stage of remission more safely, and perhaps more quickly:

\section{Effects of Secretion}

At doses given four times daily which produced no sideeffects poldine (Acred, Atkins, Bainbridge, Brown, Quinton, and Turner, 1957) has been shown to reduce the gastric secretion of acid under basal conditions (Seidelin, 1961), in response to food (Mitchell et al., 1962), in response to distension test meals (Douthwaite and Hunt, 1958), and in response to maximal doses of histamine (Seidelin, 1961). Because the secretory responses to a variety of stimuli are correlated on an ordinal scale (Hunt, 1950), we have used the changes in response to a distension test meal as an index to the variations of the secretory responses to all stimuli.

In this study the reduced secretion of acid, as measured on active tablets, remained steady for up to seven years without any change in dose. On stopping active treatment after four years, unexpectedly the secretion of acid did not return to the initial untreated value. However, there was no evidence of this reduction when the patients were on inactive tablets after only six months of active treatment. At present we do not regard this long-term reduction of secretion, as measured when the patients were on inactive tablets, as being a direct effect of poldine, but as a manifestation of the course of the disorder, which is consistent with the view of Littman (1962). This reduced secretion on inactive tablets was maintained in group II for at least two and a half years. We regard this value as the "norm" for our patients when they are well and not receiving drug treatment. In comparison with this norm, secretion of acid in hospital before treatment was raised. Also, on inactive tablets it was raised in outpatients after only six months of treatment with poldine. This may indicate that there was a predisposition to active ulceration at these times.

The effect of poldine on the combined acid and alkaline secretions resulted in a reduction by one-quarter in the concentration of acid in the mixed gastric juice. This reduction was consistent with the results of Kay and Smith (1956) in testing the action of a single intramuscular dose of atropine sulphate on nocturnal secretion. During treatment with active tablets the amount of pepsin was reduced by about half compared with the norm, since the reduction of pepsin secretion was relatively greater than that of acid secretion. In this study these reductions stemed to be sufficient to prevent symp- toms and complications in most of the patients most of the time, even if they were high secretors.

Gastric Emptying.-The changes in gastric emptying were negligible in most patients, even in the patient (Case 8) who had severe stenosis at a subsequent operation.

\section{Double-blind Study}

It is now clear that the double-blind study was made on patients whose gastric secretion, as measured on inactive tablets, had been more or less permanently decreased after two to four years of treatment with poldine. This prevented each patient being used as his own control. It also prevented group I from being used as a control for group II, and vice versa, during the six months of the double-blind trial. In an attempt to overcome this the trial was prolonged in the expectation that group II, on inactive tablets, would provide a control for group I, on active tablets. This hope was thwarted because group II, although randomly selected, secreted much less acid than group I $(P=0.05)$.

\section{Clinical Effects of Poldine}

Since the last report of the clinical progress of the 15 patients in this trial 11 have been practically symptom-free and have lost no time from work, whereas before treatment with poldine they were all losing time. If we bear in mind their previous history, this result seems likely to be the effect of treatment. However, it was not possible to distinguish between the clinical effectiveness of active and inactive tablets tested under doubleblind conditions in those patients who had received prolonged treatment with poldine, because they did not often relapse or have pain.

Only nine patients recorded any symptoms at all in three years on tablets under blind conditions. Only two patients regularly recorded pain or discomfort-Case 8 recorded 203 symptom-units and Case 16190 units. The other seven recorded $71,60,52,49,41,13$, and 10 symptom-units respeatively during infrequent bouts. It was found that the 10 highest secretors included the nine patients who recorded any pain. The amount of acid secreted, as measured before treatment in hospital and on inactive tablets after six months of treatment, was correlated with the recorded incidence of pain at the 1-in-200 level, the Spearman Rank correlation coefficient (Siegel, 1956) being used.

\section{Clinical Histories of Patients who Relapsed}

It is of interest to consider in detail the four patients who had N recurrences of illness during the trial.

Case 4.- In June 1962 this patient, then aged 66, had a bout of symptoms at the end of his period on inactive tablets. His mean secretion of acid on active tablets was $65 \mathrm{ml}$; 佂 inactive tablets month by month the values were 70, 57, 117, and $127 \mathrm{ml}$., $\omega$ the last occurring when he was having pain. Within five days of his starting active tablets the pain was relieved. He had another 0 bout of pain in October 1962 on active tablets, but his symptoms were not entirely similar to those which he had previously recorded, ? On known active tablets he recovered within a week. He was away 0 from work for four weeks. We conclude that his first bout of pain in June 1962 was caused by the rise in gastric secretion of $\overrightarrow{\mathbb{D}}$ acid when he was on inactive tablets. We have no information about his gastric secretion during the second bout in October 1962 . Since his gastric secretion of acid is high and can be reduced with poldine we believe that his usual freedom from pain may be 8 attributable to the treatment.

Case 6.-This patient, now aged 74, has severe rheumatoid arthritis for which he finds it necessary to take 6 to 12 aspirin tablets a day. He had a history of two years of mild epigastric pain in 1957, but was brought into the trial because he had a severe melaena. At that time he had nocturnal frequency and a poor urinary stream. In May 1960, while on active tablets, he was admitted with prolapsed piles. On being put to bed he 
developed acute retention, which was relieved by prostatectomy. He has had no further epigastric pain, but had another melaena in September 1964 after two years on inactive tablets. A further melaena in March 1965 was treated by a Billroth II partial gastrectomy. There was a severe deformity of the pyloric region, which was fixed to the pancreas. Before treatment his gastric secretion of acid was $69 \mathrm{ml}$, which was reduced to $37 \mathrm{ml}$. during the first six months on active tablets. He was on inactive tablets up to September 1964, his secretion of acid remaining at $77 \mathrm{ml}$. After the melaena his secretion on active tablets fell to $56 \mathrm{ml}$. His melaena in March 1965 was also preceded by a value of $70 \mathrm{ml}$. recorded after he had been accidentally given double-blind tablets which were inactive. Thus we know that his two episodes of melaena were preceded by gastric secretion of $70 \mathrm{ml}$. of acid. However, he had secretions as high as this on a number of occasions not followed by melaena. He is probably the patient most likely to bleed in our series, being the oldest and the only one who takes aspirin.

Case 8.-This patient had a perforated duodenal ulcer in 1954. When he came into the trial in 1957 he gave a history of severe pain in the back and epigastrium, which required 10 weeks of treatment in hospital. He had a large stomach with evidence of slow gastric emptying, but he refused surgical treatment. Eventually he was persuaded to have a pyloroplasty and vagotomy in 1965 because his gastric secretion of acid was gradually rising, and be became acutely obstructed. On inactive tablets as an outpatient, after only six months of treatment with active tablets, his gastric secretion of acid was $168 \mathrm{ml}$., whereas on active tablets initially it was $107 \mathrm{ml}$, gradually falling to $72 \mathrm{ml}$. before the blind trial. During three months when he was on inactive tablets under double-blind conditions his secretions of acid at monthly intervals were $133,117,131$, and $191 \mathrm{ml}$., during which time he had such severe pain that he was given known active tablets. He was improved by these, but continued to have occasional symptoms. By 1965, while he was on continuous active tablets, his secretion had risen to a mean of $130 \mathrm{ml}$. over six months, with $192 \mathrm{ml}$. on one occasion. During treatment under double-blind conditions a recovery of $538 \mathrm{ml}$. of gastric contents was obtained on active tablets, and of $478 \mathrm{ml}$. on inactive tablets. From this history we conclude that poldine is effective in reducing gastric secretion in a patient with slow gastric emptying and a very high secretion. There seems to be little risk of poldine producing undue slowing of gastric emptying in such patients.

Case 15.-This patient, now aged 63, first had a gastric ulcer in 1945, but no further symptoms occurred until 1956. From October 1956 to June 1957 he was treated unsuccessfully at home with rest in bed, having long spells off work. Because of an increase in size of his ulcer he was admitted to hospital. On treatment with poldine in hospital he rapidly became free of pain, and the ulcer had healed by August 1957. His secretion of acid on inactive tablets, after the first six months on active tablets, was $55 \mathrm{ml}$. On active tablets the secretion of acid remained at about $20 \mathrm{ml}$. until he developed flatulence and vomiting in November 1963, when it suddenly increased to 43 and $47 \mathrm{ml}$, and recurrence of his ulcer was seen radiologically. After the treatment in hospital his ulcer healed and has remained so on active tablets. We conclude that the reduction in gastric secretion of acid from $55 \mathrm{ml}$. to $20 \mathrm{ml}$. may have prevented the recurrence of gastric ulcer. When his secretion rose he had a recurrence of his ulcer. It is interesting that the norm for this patient was $35 \mathrm{ml}$. of acid. Thus, although he did not have absolute hypersecretion at any time, when he had a relapse he secreted one-third more acid than he did when healthy. We do not know whether he was exposed to special stress, but there are several instances of hard physical work, worry, or unpleasant experience being associated with rises in gastric secretion of acid in patients receiving poldine, and in healthy subjects (Douthwaite et al., 1961 ; Hunt, 1950).

\section{Conclusions}

This trial has produced evidence that treatment with poldine is an effective means of reducing gastric secretion of acid and is an effective means of reducing we he have failed to show that, after four years of treatment with poldine, patients given inactive tablets will relapse. However, this may be explained by the finding that after this period of treatment the gastric secretion of acid remains below the pretreatment level for up to two and a half years in most patients.

Three patients relapsed while on inactive tablets ; one relapsed on active tablets. We regard this evidence as equivocal.
There was a correlation between recorded pain and pretreatment secretion of acid.

Since poldine is as effective as vagotomy in reducing the secretion of acid by the stomach but has no significant undesirable actions, we suggest that it can be used in the treatment of duodenal ulceration in place of vagotomy provided there is no significant obstruction to gastric emptying. In our two patients with gastric ulcer poldine was effective in reducing gastric secretion of acid, and they fared well clinically.

\section{Summary}

Gastric secretion of hydrochloric acid, bicarbonate, and pepsin has been studied in patients with peptic ulceration treated with poldine methylsulphate for periods greater than five years, part of the time under double-blind conditions.

During this long period of treatment with active tablets the gastric secretion of acid, as measured on inactive tablets, had fallen, and had not risen again within 30 months (in patients continuing on inactive tablets). The secretion of acid on inactive tablets after prolonged treatment is thought to be the norm for the patients. The raised secretion of acid before treatment began and after only six months of active treatment is thought to indicate a predisposition to active ulceration at these times.

The halving of the gastric secretion of acid, relative to the pretreatment value, has been maintained for up to seven years by unchanged doses of poldine which did not cause undesirable effects.

Poldine reduced the concentration of acid in the gastric secretion in response to test meals from 100 to $75 \mathrm{mN}$. The output of pepsin was reduced more than the output of acid.

There was very little dyspepsia among these patients while they were on active tablets. Under double-blind conditions most patients did not relapse on inactive tablets. This might be attributed to the reduction in gastric secretion during longterm treatment with poldine.

Patients with high secretions of acid while on inactive tablets during their original illness recorded more pain throughout the whole trial than those with low secretions.

Though gastric emptying was slowed by about one-tenth by poldine, the long-term increase in the rate of gastric emptying during the period of treatment more than offset this slowing.

Undesirable toxic actions on the bone-marrow, liver, or kidneys were not detected.

No significant effect on intraocular pressure was found, even in a patient with a shallow anterior chamber.

Since poldine reduces gastric secretion by one-half, as does surgical vagutomy, but has no significant undesirable actions, it may be considered for the treatment of duodenal ulceration in place of vagotomy where there is no significant obstruction to gastric emptying.

We are grateful to Beecham Research Laboratories for generous supplies of Nacton during this investigation and to our clinical colleagues for referring patients.

\section{REFERENCES}

Acred, P., Atkins, E. M., Bainbridge, J. G., Brown, D. M., Quinton, , M. And Turner, D. H. (1957). Brit. Ұ. Pharmacol., 12, 447.

Bell P. R. F (1964). Gastroenterology, 46, 387.

Brit med f 1963,2 , 1387.

Douthwaite, A. H., Hills, T. H., and Hunt, J. N. (1961). Brit. med. F. 1,1575 .

- and Hunt, J. N. (1958). Ibid., 1, 1030

Fry, J. (1964). Ibid., 2, 809.

Grossman, M. I. (1963). Physiologist, 6, 349

Hunt, J. N. (1950). Gastroenterology, 16, 231

(1954). Guy's Hosp. Rep., 103, 161.

Kay, A. W., and Smith, A. N. (1956). Brit. F. Pharmacol., 11, 231.

Kay, A. W., (1962) Gastroenterology, 43, 166.

Mitchell, R. D., Hunt, J. N., and Grossman, M. I. (1962). Ibid., 43, 400.

Seidelin, R. (1961). Brit. med. 7., 1, 1079.

Siegel, S. (1956). In Nonparametric Startics for the Behavioural Sciences, p. 202. McGraw-Hill, Lond $\cdots$. 